\title{
Applying a conceptual design framework to study teachers' use of educational technology
}

\author{
Jörgen Holmberg ${ }^{1,2}$ (D)
}

(C) The Author(s) 2016. This article is published with open access at Springerlink.com

\begin{abstract}
Theoretical outcomes of design-based research (DBR) are often presented in the form of local theory design principles. This article suggests a complementary theoretical construction in DBR, in the form of a design framework at a higher abstract level, to study and inform educational design with ICT in different situated contexts. Laurillard's Conversational Framework (CF) is used as a conceptual lens to analyse how eight teachers use or envisage using technology to support learning in one-to-one environments. The findings demonstrate how the researcher uses the $\mathrm{CF}$ to discern different aspects of the teachers' situated design practices. In the study, ICT is primarily used to support communication and the exchange of knowledge representations between the teachers and their students. Considerably fewer examples are found where ICT is used to support communication, collaborative creation and modelling between peers. However, the interview analyses reveal that the teachers' intentions to apply ICT to support learning often include this second type of ICT use. Reasons for this discrepancy between the expressed intentions and de facto use of ICT include limitations in technical know-how and a perceived conflict between collaborative learning, existing school cultures and individual assessment. The findings suggest that in DBR, an analytical design framework could be an important tool for researchers and teachers when analysing and discussing educational uses of ICT. The CF provides a promising basis for a design framework, but should be expanded to include interactions with actors outside the classroom.
\end{abstract}

Keywords Design-based research · Design framework - Educational design · EFL . Conversational framework $\cdot$ Teacher

Jörgen Holmberg

jorgen.holmberg@hig.se

1 Department of Educational Sciences, University of Gävle, Gävle, Sweden

2 Department of Computer and Systems Sciences, Stockholm University, Stockholm, Sweden 


\section{Introduction}

Design-based research (DBR) is recognised as a promising research approach for studying teachers' situated use of information and communication technologies (ICT) (Albion et al. 2015; Plomp and Nieveen 2013; Yun Dai 2012). However, as with educational research in general, DBR has been criticised for a lack of theoretical grounding and an insufficient use of theoretical models in studies of teachers' educational designs with ICT (Gunn and Steel 2012; Kirkwood and Price 2014; Selwyn 2012). Educational research also appears to offer limited research-based advice for teachers seeking to reframe their practices in complex and increasingly digitised contexts (Anderson and Shattuck 2012; Reeves et al. 2011). These perceived shortcomings are suggested as reasons why many teachers do not explore the possible pedagogical added values of ICT (Vrasidas 2015; Wastiau et al. 2013). This article presents an alternative to the current focus of DBR on designed interventions and theory development in the form of design principles. It is suggested that the locus of attention in DBR should be widened to include teachers' design thinking and the formulation of a theoretically underpinned design framework to study and support such thinking. Previous DBR indicates that both researchers and teachers would benefit from such a theoretical (Gravemeijer and Cobb 2006; Sandoval Sandoval 2004).

This article reports on a study in which an existing model, Laurillard's Conversational Framework (CF), is applied as a potential design framework to analyse how eight teachers' use, or express their intentions to use, ICT in one-to-one contexts.. ${ }^{1}$ The objective is to analyse the extent to which teachers' design intentions and their de facto use of ICT support the different communicative cycles in the CF. The following research questions are formulated:

1. Are there design intentions or practical educational design elements in the data that cannot be described using the $\mathrm{CF}$, and if so what are their characteristics?

2. How are the communicative cycles in the CF supported by the teachers' de facto use of ICT in educational designs?

3. How are the communicative cycles in the CF supported by the teachers' expressed intentions for educational design with ICT?

\section{Background}

\subsection{The idea of a design framework as a theoretical construct in design-based research}

More than a decade ago, Sandoval (Sandoval 2004) commented on the need for theory development in DBR. He argued that a theoretical framework was necessary in order to more systematically study educational design in different contexts and to develop a more general theoretical knowledge that would inform educational design in other than localised contexts. Gravemeijer \& Cobb make a distinction between two different

\footnotetext{
${ }^{1}$ In one-to-one laptop programmes the school provides every student with a personal computer which they can use at school and at home. 
approaches to the development of theories in DBR: the development of local instruction theories and the development of 'theoretical frameworks that address more encompassing issues' which could be used at a higher abstract level to guide teachers' design for learning (Gravemeijer and Cobb 2006, p. 19). However, more recent research indicates that DBR has mainly focused on developing local instruction theories in the form of design principles as outcomes of interventions to meet local design challenges (McKenney and Reeves 2012, p.36). Anderson and Shattuck (2012) conclude that although DBR is a promising research approach, its aim to provide theoretically based generalisable advice for educational designers has not yet been realised. Holmberg (2014) suggests shifting the focus of attention in DBR from the practical intervention and its characteristics to the teacher's cognitive processes and actions before, during and after the design process. A shift in focus from design product to design process and teachers' design thinking would also mean a change in the theoretical contributions of DBR. A theory-based and empirically tested design framework could provide researchers with a tool to study teachers' design with ICT in different situated contexts. Instead of being restricted to what has worked in a certain context for a certain problem, a conceptual design framework could also help to support teachers' design thinking at a more general level. Conceptual frameworks are context independent in the sense that they retain their basic "meaning" regardless of the context. However, the unique context in which they are applied also affects how they are enacted in practice. In education, Biggs' idea of 'constructive alignment' is an example of a conceptual framework that underlines the importance of aligning curricular objectives, the activities performed by the teacher and students and the teachers' assessment of students' learning outcomes (Biggs and Tang 2011). Although the idea of alignment as a 'framework' can be applied to different educational settings, the formulation of specific learning outcomes and the choice of educational activities will always be adapted to the unique design context. A design framework would aim to represent the roles of the teacher, the individual student and peer learners in their individual and collaborative meaning making. Gravemeijer \& Kobb suggest that the complexity of educational contexts imply the need for a broad design framework in DBR and one that incorporates '...general background theories such as socioconstructivism, or sociocultural theory, domain-specific theory and theories on specific elements of the learning ecology...' (Gravemeijer and Cobb 2006, p. 48).

\subsection{Previous research on learning and teaching}

Research indicates that a successful educational design is one in which the learner's preconceptions are elicited and where the learner is encouraged to build on, modify or refute these preconceptions (Bransford et al. 2000). Successful learners develop subject specific conceptual frameworks that allow them to understand, select and critically interpret new information (Biggs and Tang 2011). This insight is closely connected to research findings that stress the importance of learners developing metacognitive strategies and teachers creating designs that help students to develop such strategies (Bransford et al. 2000). There is also evidence to suggest that learners benefit from multimodal examples and variations of the concepts, ideas and skills to be learned, preferably in different contexts (Hattie and Yates 2014; Marton and Pang 2006). These research based insights are useful for teachers considering using ICT to support every 
learner's cognitive process. However, social constructivist and sociocultural theories of learning, and more recently connectivist perspectives of learning, emphasise the social aspects of learning (Rogoff 1995; Siemens 2005; Weick 1995; Wertsch 1991; Wenger 1998; Vygotsky 1986; Zittoun and Brinkmann 2012). In line with this research, in this article learning is discussed in terms of meaning making:

"Learning as meaning making" is an expression emphasizing the fact that in any situation of learning, people are actively engaged in making sense of the situation - the frame, objects, relationships - drawing on their history of similar situations and on available cultural resources. (Zittoun and Brinkmann 2012, p. 1809)

Viewing learning as meaning making means that a central concern for teachers is how to stimulate and support an exchange of knowledge representations, and communications about these, between teachers and student(s) and between students. A theoretical added value of ICT is its potential to stimulate and support this exchange in new ways (Sawyer 2014; Spector et al. 2014). Thus, a design framework could be used as a model or an analysis tool when looking at or thinking about educational designs.

\subsection{Educational design to support meaning making}

Vygotsky illustrates how learning through communication is different from learning through instruction and practice. When learners communicate and express ideas, they contribute to what it means to know these ideas and how this can be expressed in speech. This illustrates how thought 'does not merely find expression in speech; it finds its reality and form’ (Vygotsky 1986, p. 219). Similarly, Weick emphasises that learning is about making meaning that materialises through communication (with others and oneself) and 'about authoring as well as interpretation, creation as well as discovery' (Weick 1995, p. 8). Papert (1980) maintains that an especially powerful way of learning through interaction and communication is individual and collaborative learning-bymaking. This process includes an externalisation of ideas, which makes them tangible and allows individuals to 'see their thinking'. When we act on the world together with others we also make our ideas and knowledge shareable and communicable. Drawing on the research discussed above, it is possible to argue that a central part of a teacher's work is to support meaning making by stimulating and supporting the exchange of and communication about abstract conceptualisations in the form of knowledge representations between teachers and students and between students. By using ICT, the process of meaning making can theoretically be supported across the boundaries of time and space and through different modalities (Sawyer 2014; Spector et al. 2014; Stahl et al. 2014). However, as indicated at the beginning of this article, previous research indicates that teachers could benefit from support in this. A number of theoretically informed conceptual models and frameworks with various foci, complexities and levels of abstraction are available to help us understand the different aspects of educational design with technology. ${ }^{2}$ The Conversational Framework (CF) was developed by Diana Laurillard with the intention of supporting teachers in their design with ICT (Laurillard

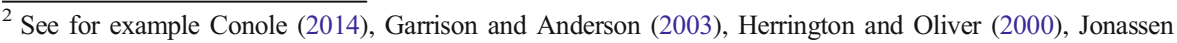
(1999), and Luckin (2008).
} 
2002, 2012). IT has been applied in various learning settings and subject areas (Sharples et al. 2007). In line with the above discussion about learning as meaning making, the CF recognises the interdependence of individual and social processes in learning and that an educational design should reflect this by creating conditions for communication and the exchange of knowledge representations between individual learners, teachers and peers (Laurillard 2012). The CF represents the roles played by these actors in formal learning contexts and can thus provide a conceptual framework for how teachers, through the use of ICT, could design a teaching-learning environment for multimodal 'conversations' between them.

\subsection{The conversational framework}

In Laurillard's model, the individual learner is placed at the centre (see Fig. 1). The grey area represents what Laurillard refers to as the learner's internal learning cycle. Laurillard describes how the teacher's role is to 'motivate the internal cycles generating and modulating the learner's concepts and practice, which is what facilitates learning' (Laurillard 2012, p. 86). An individual learner can interact with other actors by means of five communicative cycles at two levels: the conceptual level and the practice level. At the conceptual level, the students' meaning making processes are supported by communication about what is to be learned (Laurillard, p.87). An example of learning supported at the conceptual level is when a teacher explains something orally and the individual student or peer asks a question or generates an articulation of his/her own conceptualisation. The teacher can then answer the question and give feedback on the articulations. This is known as the teacher's communication cycle (TCC). When the individual learner and peers exchange articulations of their concepts, for example when discussing how to interpret a text or solve a problem, this takes place in what Laurillard refers to as the peer communication cycle (PCC).

However, a learner's conception of what is to be learned can also be expressed or supported at the 'practice level' (Laurillard 2012, p. 89). In formal learning contexts, ICT can be used to design what Laurillard refers to as a teacher's practice/modelling environment (TPME). Here, students can participate in a number of (learning) activities, primarily with their teacher and peers, although the use of ICT increasingly permits

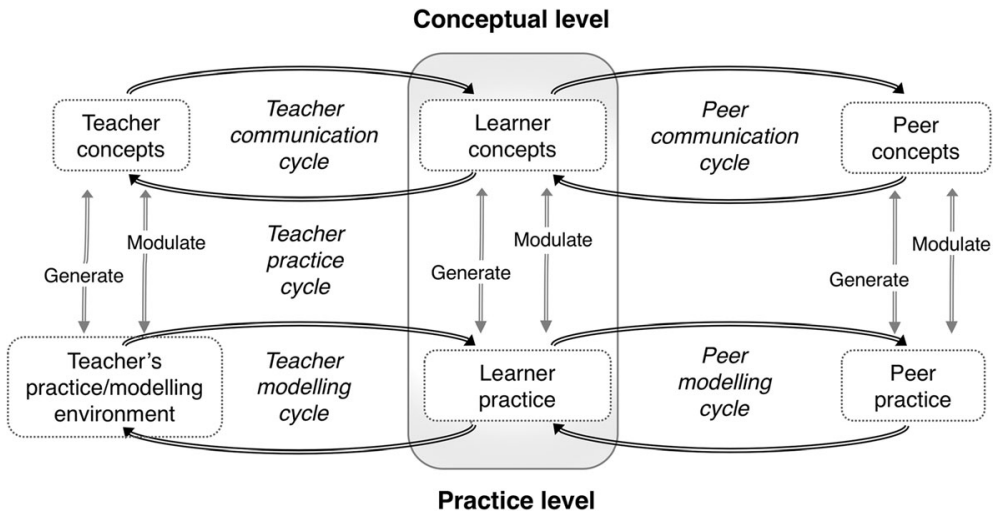

Fig. 1 The conversational framework (Laurillard 2012) 
interactions with external actors. In the TPME, the individual learner and peers act on the external environment by applying concepts. Thus, the individual learner's practice and the peers' practice are represented in the TPME as representations indicative of the students' understanding. The teacher can give feedback in relation to these representations in the teacher practice cycle (TPC). ${ }^{3}$ The TPC can thus help the learner 'connect' a representation at the practice level with the concept that is to be learned, thus supporting the learner's internal learning cycle. The TPC also provides teachers with feedback on their teaching and whether students are learning what is intended.

When an ICT-supported educational design provides learners with feedback on their practices, Laurillard refers to this as the teacher modelling cycle (TMC). The inclusion of an educational game that gives learners automated feedback is an example of this. Finally, in designs that support the peer modelling cycle (PMC), learners are enabled and motivated to share and access peer representations in the TPME. These knowledge representations could then be used in the PMC by other students for modelling independent of time and place. They could also be referred to at the 'conceptual level' as examples of what is to be learned, i.e. as part of the TCC or PCC. In short, Laurillard's Conversational Framework provides an overarching theoretical design frame for thinking about how to assist and encourage learning using technology to support meaning making.

\section{Research design}

This research is part of a larger DBR project. In the study, the CF serves as a conceptual lens in order to analyse the participating teachers' educational design with technology. In the next phase of the DBR project the Conversational Framework, or a modified version of it, will be applied to support practical educational design in different contexts. In this study, the author primarily functions as a researcher and does not contribute to the practical design, but simply observes, discusses and analyses the teachers' design intentions and enacted educational designs.

\subsection{Context and participants}

The author studied the design practices of eight experienced upper secondary teachers of English as a foreign language (EFL) in four Swedish municipal schools with one-toone laptop programmes. Collaboration with as many as eight teachers could be considered atypical in DBR. However, when examining the usefulness of a more generic conceptual construct (i.e. the $\mathrm{CF}$ ) as an analytical design framework, applying it as a conceptual lens in different design contexts was considered important (Barab 2004). Empirical data was collected over a period of fifteen weeks, starting in December 2014. The teachers had all taught English for more than six years and had volunteered to participate in the project after they and their colleagues had received information about it. They all had a positive attitude as far as the pedagogical potential of ICT was concerned and considered themselves somewhat more 'tech savvy' than the average colleague. Nevertheless, all but two of the teachers claimed that their

\footnotetext{
${ }^{3}$ In Fig. 1 the TPC is thus represented by the top and bottom arrows on the left-hand side of the model.
} 
technological knowledge was limited and needed to be substantially developed. This was the first DBR project they had participated in. During the study the author met each of the teachers three times. Other means of communication were used between these sessions and are described in the data collection section below. Together with each teacher, the author decided which of the teacher's classes to focus on to follow his or her authentic design practice. ${ }^{4}$

\subsection{Data collection and data analysis}

The primary data consists of open-ended audio recorded interviews lasting between fifty to sixty-five minutes. In total, nineteen hours of recorded material were transcribed. These interviews are hereafter referred to as design conversations, because they relate to a practical educational design that had been carried out or a design intention that might be carried out at some stage. The design intentions vary between general and specific ideas about how technology can be used to realise certain pedagogical intentions. The design conversations often involve both the researcher and teacher looking at and interacting with an educational design in use, or an idea for an educational design, as represented on a computer screen or occasionally on a piece of paper.

A second source of data is the teachers' educational designs that they created and used in their digital teaching environments, and to which the researcher had full access. A third source of data is the reflective logs that the teachers were asked to keep and share with the researcher between the design conversations. Thirty-one log entries were received, varying in length between some 60-250 words. A fourth source of data is the researcher's own field notes. The triangulation of data sources described above enabled the researcher to capture different dimensions of the teachers' practices and arguably contributed to the trustworthiness of the analysis process (Flick 2014; Miles and Huberman 1994).

In the first part of the analysis process the collected data is coded and analysed according to the principles of what is referred to as a directed (Hsieh and Shannon 2005), or deductive (Elo and Kyngäs 2008) approach to qualitative content analysis. This approach is often used when the goal is to validate or conceptually extend a theoretical framework, model or theory (Elo and Kyngäs 2008, p. 111; Hsieh and Shannon 2005, p. 1281). The CF is used to inform a coding frame referring to its five different communicative cycles. An additional "Other" category is included too. In the event that data is considered to relate to an idea about or an example of technologysupported design to support learning, but cannot not be coded using the five categories in the matrix, it is coded "Other".

During the reading of the transcribed design conversations and the teachers' written reflective logs, the researcher selected, but did not code, the parts of the text relating to the educational use of technology. Here, the intention was to not use the CF as a conceptual lens. This was done in an attempt to increase the trustworthiness of the analysis by making the researcher 'see' other uses of technology to support learning

\footnotetext{
${ }^{4}$ Of these upper secondary school classes, four studied the English 5 course in the Swedish curriculum (first year) and three the English 6 classes (second year). One class of students in their third and final year of upper secondary school studied English 7.
} 
that corresponded with the communicative cycles in the CF. In the next step of the analysis, the selected passages were coded using the six main categories described above. It was decided that if the "Other" category was used extensively during the coding it would indicate that the initial coding frame needed to be revised. During the coding the researcher read the selected passages in the transcriptions while simultaneously listening to the original recording of the passages. This was done in order to pick up on nuances, pitch, hesitations and so on that were not reflected in the written transcript but that could be important when interpreting and understanding the data. The same procedure was used two weeks later, when the passages were double-coded by the researcher to increase intracoder reliability. In the next step of the analysis the researcher read through all the coded examples again, inductively coding and categorising the data segments with the intention of identifying salient features of use in the main categories and sub-categorising them. This step of the analysis was repeated a second time two weeks later.

\section{Results}

It should be stressed that the findings only relate to how the teachers envisioned and make practical use of ICT in the communicative cycles. How and whether the communicative cycles were enacted in the physical classroom without the use of ICT has not been analysed. The findings are presented in relation to the communicative cycles in the CF. Under each heading, the salient features related to the teachers' intentions for and de facto use of ICT to support learning are presented.

\subsection{The teacher communication cycle (TCC)}

The study shows that all the teachers frequently used ICT to support the TCC. Using texts and videos from the Internet to provide students with authentic and current examples of English in use was a common example. The ability to use the Internet to 'connect to the real world and show how English is used there' is mentioned as important to motivate students to study and 'buy in on' what the teacher has planned for the class. Another common design element, displayed both as intentions and practical use, is multimedia artefacts with explanatory potential, such as PowerPoints or Prezis. These are often created by the teachers themselves, or have been shared by a colleague or discovered on the Internet. The use of ICT thus provides teachers with an opportunity to explain concepts by using artefacts constructed by external actors. Authentic examples of English in use is a similar ICT-supported design element used by all the teachers in the TCC, most frequently in the form of texts and videos.

Sometimes the multimedia artefacts created by the teachers relate to authentic examples and can be seen as examples of cognitive apprenticeship (Collins and Kapur 2014). The intention of the teacher as the expert is to give students access to his/her thinking in relation to the authentic example. Students can then use this to model their own conceptualisations. However, when analysing this practice it was found that the authentic examples and the designed artefacts were not integrated, but presented as two separate objects in the LMS. In discussions with the teachers, it became evident that the idea of guiding students what to pick up from an example was 
intended as an integrated 'overlay' or commentary in direct relation to what the teacher wanted the students to observe and understand. In other words, the teachers' comments were intended to become an integrated part of the authentic example, rather than an artefact in its own right. Unfortunately, the teachers lacked the technical know-how or 'technology knowledge' to make this happen (Koehler and Mishra 2009). In the next phase of the DBR project, YouTube text annotations and screencasts are examples of technologies that could be used to this effect.

ICT is also occasionally used in the TCC to allow students to ask the teacher questions. This is done via the email or forum function in the LMS. The perceived added value is that a student who has not been able to attend class, or has not wanted to ask a question in class, can do so. Two of the teachers also used the LMS forum as a (b) $\log$ to summarise what had been done in the lesson and what needed to be done before the next one. Here, the teachers' intentions were that (in theory) students could relate this to their own study and learning processes by scrolling through the planning and catching up on what had been missed in class.

\subsection{The teacher practice cycle (TPC)}

The teachers in the study frequently use ICT to support the TPC. The most common way in which this is done is by asking students to submit individual assignments in the LMS and to use the functionality of the LMS for feedback from the teacher. The student representations and teacher feedback are almost exclusively in written form, occasionally complemented with images. The possibility of students using ICT to practise their oral English and send a recording of their performance to the teacher for feedback was not taken advantage of during the course of the study. Similarly, the researcher did not find any examples of the teachers using recorded voice comments or screencasts for feedback. However, some of the teachers did make use of the recordings of students' oral performances during the annual compulsory national tests in English. Nevertheless, in discussions about the potential of ICT to create an added pedagogical value, audio- and video recordings of students' performances were mentioned by all the teachers. The recording of students' performances was envisioned as a way of making assessments more 'accurate'. Other statements indicated that such recordings facilitated more specific and qualitative formative feedback and alleviated the pressure on teachers during a 'live assessment'.

Reasons for the limited use of ICT to record, share and comment on knowledge artefacts in audio or video format included a lack of familiarity with the software and hardware and students' limited ICT skills. All but two of the teachers (who had special role as ICT coaches for other teachers) expressed having limited experience as far as this type of technology and software were concerned. None of the teachers came up with a strategy for selecting and commenting on a particular part of a recorded oral performance in a way that would be helpful to the students. The extra time that this kind of commenting was expected to take was also mentioned as a deterrent (Tallvid 2016).

\subsection{The teacher modelling cycle (TMC)}

Like the TPC, the TMC typically involves the construction of exercises that generate learners' representations that are indicative of their current conceptualisations. 
However, in the TMC, feedback on student representations comes from the modelling environment, for example in the form of automated feedback from a web application. In the study, the teachers used ICT to support the TMC, although to a lesser degree than for the TCC and the TPC. The examples included web-based resources for vocabulary or grammar practice with automated feedback. Given that all the students had access to computers with word processing software, including spelling and grammar checks, this type of ICT-supported feedback was also included. However, when asked what type of ICT the teachers or their students frequently used, none of the teachers specifically mentioned word processing software. This is one of several examples in the study of how technology, and how it can be used, can become a natural part of the teaching practice and, as such, taken for granted. Educational games were mentioned in relation to the TMC as having a potentially motivating effect on learners, especially those with a competitive spirit, but were in fact only used as an optional 'extra'. As an explanation for this, one teacher stated that by and large educational games were 'too basic'. Another teacher said that 'they do not deal with what we [the class] learn'. When asked what was meant by this statement, the teacher answered: 'They [the students] already have a varied vocabulary and know how to spell.' The fact that the TMC was only used for lexical and grammatical core skills was interpreted as a sign of how the teachers saw limits to the kind of learning that could be supported in the TMC. Teachers who taught students assessed as proficient in English also used the TMC to a lesser extent than those teaching less proficient students.

\subsection{The peer communication cycle (PCC)}

In the study, ICT was used to support the PCC to a considerably lower degree than the TCC and the TPC. Only one of the teachers created and asked students to use an ICTsupported design element (a reflective blog) to support the PCC. Here, the students formed discussion groups of three in which they were encouraged to read and comment on the reflections expressed in each other's blogs. The primary intention with the blog was to stimulate metacognition. Two teachers regularly used an online 'bulletin board' to stimulate the PCC. Here, students could suggest topics for writing assignments and share experiences related to their English education. Although the practical use of ICT to support the PCC was limited, six of the eight participating teachers mentioned the ability to use ICT for school-related discussions at different times and in different spaces as a possible added value of ICT. They expressed that this happened spontaneously between the students, but also between students and external actors (for example friends or relatives) when they used their mobile phones or computers to discuss school work. Whether these types of conversations actually encouraged students to compare their conceptualisations to support meaning making is not clear. Nevertheless, the ubiquity of communication devices means that learners are able to communicate with actors outside the classroom (e.g. as part of the PCC) and to model their practices on those of others outside the classroom (e.g. as part of the PMC). One of the goals of English education in the Swedish upper secondary school is to develop 'The ability to discuss and reflect on living conditions, social issues and cultural features in different contexts and parts of the world where English is used' (Skolverket [Swedish National Agency for Education] 2011, p. 54). In relation to this goal, one of the teachers expressed an intention to include a design element that enabled students to use ICT 
to contact relatives, friends or acquaintances living in a country in which English was an official language. Email or video call services were also discussed as digital tools that could be used in such a design element.

Five of the eight teachers mentioned blogs as a tool they had considered but decided not to use. The primary reason for this was a reluctance to 'force' students to create personal accounts with a blog service provider and have to remember yet another password. Another reason was that their students were not used to writing reflectively about their learning or giving each other feedback in relation to this. This was indicated by statements such as 'we don't have that kind of culture', which suggested that learning was largely seen as an individual activity. Thus, there was a concern that if a blog or other digital tool was used to support the PCC it might not have the desired effect. In addition, the LMS had no built in blog functionality, which the teachers said they would have considered had it been available. When these uses were discussed, the focus was on communication with peers as classmates and on a personal (b)log to support metacognition.

\subsection{The peer modelling cycle (PMC)}

In the PMC, learners are motivated to share representations of their practices in the TPME with peers by collaborating and/or learning from each other in some way. In both cases, the PMC allows learners to model their practices on those of their peers (e.g. how they speak or write English). Due to the nature of EFL education, it was sometimes difficult for the researcher to decide (and thus code) when designs or intentions were aimed at supporting the PCC, the PMC, or both. In EFL, students' abilities to communicate in the target language are tested as a learning goal. However, as all the classes in this study consistently used English in conversations, the students had constant access to peer concepts (i.e. through the PCC) for modelling purposes (i.e. through the PMC).

In the study, ICT was used to support the PMC to a considerably lesser degree than the TCC and the TPC. Group assignments were often included in the teachers' designs. However, the analysis showed that ICT was rarely used to stimulate or necessitate collaboration. Neither was ICT used to support the exchange of and feedback on knowledge representations for modelling. For example, even though all the teachers knew about online word processing solutions for collaborative writing, none of them used such tools in their designs during the time of the study. The teachers did not use wikis or other tools either to enable the students to create and share representations for modelling. The teacher whom the researcher considered to be the most proficient in ICT reported having done this previously in the collaborative creation of an online and public newspaper. Here the teacher described a practice in which students exchanged knowledge representations for modelling and feedback, for example in the form of drafts for articles, and where feedback on published articles was possible from external actors. The teacher would have liked to continue to work in this way, but no longer had access to the ICT software and online platform that had facilitated this. Previous research on teaching and learning reports how authentic assignments and external audiences can foster collaborative meaning making (Herrington et al. 2014; Tambouris et al. 2014). Using ICT in designs for authentic assignments and collaboration is an area that will be elaborated on in the next phase of the DBR project. 
The findings of this study show that the participating teachers' designs for group work allowed students to adopt a more co-operative strategy (Dillenbourg 1999), which included dividing the work between them, writing their own parts and then putting the pieces together. Of course, the initial discussion and the final editing in this way of working could be described as having collaborative aspects but ICT was not specifically used to support such collaboration. Using for example wikis to allow students as groups to post their representations would also have encouraged meaning making by giving students access to more representations on which to model their own practices (Wang 2016; Zheng et al. 2015). Interestingly, all the teachers in the study said that they saw a potential in ICT as a tool that supported collaboration and, thus, supported the PMC. However, they stated that the focus on individual assessment, both as part of the curriculum and as expected by students, did not create an incentive to exploit these potential added values.

\subsection{The "other" category}

As already hinted at in relation to the PCC and PMC, when the teachers described their intentions to use ICT or their experiences of its use for collaborative meaning making, they did not just talk about students discussing their understanding with their classmates or modelling their practice on them. The teachers saw the Internet as an arena in which students could also engage in an authentic practice of English with external actors. In other words, ICT was seen as a means to allow students to discuss their understanding with external actors (i.e. in a communication cycle) and model their practices on them (i.e. in a modelling cycle) as part of their meaning making. At some point during the study, all the teachers discussed, or occasionally designed, some form of interaction with external actors. As an example of intentions not yet realised but considered, one teacher discussed the possibility of starting a project with another class in a partner school. Another teacher had thought about letting students find 'pen friends' in other countries. Examples where ICT was used to support modelling included the use of a web-based service called Fakebook, where students could construct and read fictional Facebook pages created by others. During the coding process, these types of ICT use were coded as the "Other" but also sub-coded as "EACC" (external actor communication cycle) or "EAMC" (external actor modelling cycle), thus indicating that ICT was used to support students' discussions or modelling practices with external actors.

\section{Discussion}

\subsection{The use of the CF as an analytical design framework to study educational design}

In this design-based study, the overarching aim has not been to inductively develop design principles from enacted design practices in situated contexts, as is common in DBR. The objective instead has been to use Laurillard's CF as a conceptual research tool to analyse how the participating teachers used and envisioned using ICT to support teaching and learning. During the analysis, the use of a design framework helped the 
researcher to focus, compare, contrast and analyse the different aspects of the participating teachers' educational designs and their potential to support meaning making. Through this analysis, a clearer picture emerged of how the teachers envisioned using and actually used ICT to support teaching and learning in different ways. Thus, the CF served its intended purpose as an analytical design framework.

However, the analysis shows that due to the pervasiveness of social media and mobile technologies, the teachers occasionally used or considered using technology to facilitate students' meaning making through conversations and/or modelling with actors outside the classroom. The teachers also reported that students, on their own accord and for learning purposes, used computers and smartphones to communicate with external actors. These findings show that technology can be used to overcome the distinction between formal- and informal learning and create more seamless learning experiences (Looi et al. 2010). In EFL education, students participating in a discussion on YouTube about a video, or receiving comments on a public blog, are examples of technology use that could support seamless learning in authentic settings (Herrington et al. 2014; Wong et al. 2015). The CF could thus be elaborated to include this type of direct interaction between learners and external actors.

\subsection{The teachers use of ICT to support teaching and learning}

The findings demonstrate that the teachers frequently used ICT to support the TCC and the TPC in Laurillard's CF. Another way of putting this is that ICT was most frequently used to support communication and the exchange of knowledge representations between the teacher and the students as a group or as individuals. The teachers used ICT to support the TMC, for example through automated feedback, less frequently than the TCC and the TPC. Moreover, when the teachers made use of design elements to support the TMC, this use only included students' learning of factual knowledge. This finding can be related to previous research, which indicates that cognitive processes can be seen as qualitatively different (Collins and Kapur 2014; Kozulin 2003). Kozulin states that 'The process of appropriation of psychological tools differs from the process of content learning' (Kozulin 2003, p. 25). He explains that 'content material often reproduces empirical realities' but that the appropriation of more complex psychological tools requires a learning activity in which the student can apply (for example when creating something), discuss, analyse and evaluate these tools in order to understand their mediational potential (ibid.). In other words, this type of meaning making requires interaction with human actors. A conceptual design framework like the CF could help teachers to make informed design decisions about which communicative cycle(s) to support and, consequently, which technology to use, depending on the cognitive process(es) in focus.

Moreover, the analysis shows that the teachers used ICT to a much lesser degree to support the PCC and the PMC than to support the TCC and the TPC. In other words, few examples were found of ICT being used to enable students to exchange and discuss knowledge representations for modelling and collaborative meaning making with peers across the boundaries of time and space. However, some research indicates that when ICT is used in this way, it could have beneficial effects (Johnson 2016). For example, by using ICT, students could theoretically have accessed all their peers' representations for modelling, which would have given them more perspectives on how to understand 
or do something (Hattie and Yates 2014; Marton and Pang 2006). Recording oral conversations and transforming them into knowledge representations also enables them to be accessed, independent of time and place, as examples to be discussed, for modelling or assessment and/or as support for metacognitive reflection.

\subsection{The teachers' intended use of ICT to support teaching and learning}

An important finding of the study is the discrepancy between the teachers' design intentions, as expressed in the design conversations, and their enacted design practice. When expressing their intentions for educational design with technology, they include the TMC, and particularly the PCC and the PMC, much more often than in their de facto design practice. In other words, the teachers' intentions to use ICT for collaborative meaning making are not always realised in practice. Identified as contributing reasons for this discrepancy are the limitations in the teachers' ICT skills, or their selfefficacy about such skills. This illustrates how, in digital contexts, informed teachers' practices not only require pedagogical knowledge and content knowledge, but also technological knowledge and an understanding of the complex and reciprocal relationship between these knowledge domains. Koehler and Mishra (2009) refer to this amalgam as technological pedagogical content knowledge (TPACK). Considering that the participants in this study are all experienced teachers who describe themselves as more technologically competent than the 'average colleague', it indicates that efforts to support the development of teachers' technological knowledge and TPACK continue to be important.

Other reasons for teachers not realising their intentions to exploit technology to support collaborative learning are related to the curriculum and students' conceptions of how school 'is done'. The use of ICT to support collaboration and formative assessment to support meaning making as a process is seen to contrast with the schools' overall teaching practices and/or students' expectations. In both cases, individual grades and summative assessments of a 'product' are the norm, rather than students working together in a community of inquiry (Dewey 1938; Garrison and Anderson 2003). Thus, the teachers' intentions to use ICT for meaning making are not always realised, in that they appear to conflict with their task of assessing individual pupils in relation to constant and measurable learning outcomes. In relation to this, the teachers express the lack of a culture for exchanging and discussing knowledge representations. These findings indicate that for a teacher who wishes to support collaborative meaning making, creating a design that supports the relevant communicative cycles in the CF may not be sufficient. Students also need to be included in a discussion about how and why they might benefit from participating in these communicative cycles.

\subsection{Conclusion}

Technology supported educational design is a complex and situated activity. In this study, the CF helped the researcher to compare and contrast eight different teachers' educational use of ICT. This analysis revealed that the teachers primarily used ICT to support communication and the exchange of knowledge artefacts between themselves and their students. To a much lesser extent, ICT was used to support meaning making through the exchange of knowledge artefacts for discussion and modelling between 
peers across the boundaries of time and space. However, when the researcher used the CF to analyse what the teachers had said and written about using ICT to support teaching and learning, its use for peer discussion and modelling was often mentioned. Reasons for the discrepancy between the teachers' expressed intentions and de facto use of ICT include limitations in their technology knowledge and a perceived conflict between the use of ICT to support collaborative meaning making, existing school cultures and individual assessment.

The findings reported here thus demonstrate how the use of an analytical design framework like the CF can be used in DBR projects by researchers to discern different aspects of teachers' pedagogical use of ICT and the potential of this use in relation to learning as meaning making. In the DBR project reported in this article the researcher could use his research findings to illustrate for the teachers the discrepancy between their expressed intentions and their design practice. The design framework could then be used as part of a meta-language in dialogues about how to use ICT more in line with their intentions. This would mean that the pedagogical rationale for implementing ICT would have to be formulated first, and that potentially suitable technology would be discussed in relation to this. DBR researchers could also use a theory-based and that empirically tested design framework as a research tool for studying how teachers reframe their practices in digital contexts.

Teachers would arguably benefit from a conceptual construct like a design framework in their efforts to individually and collaboratively discuss and evaluate how ICT could be used to create pedagogical added values. For example, a design framework could be used to analyse their own practices and to 'see' how they use or do not use ICT to support learning. It could thus be used to support their design thinking at a more general level and provide a basis for adaptation in situated design contexts. For example, as a consesquence of the results of this study the CF could be used to identify ways of using ICT to include the PCC and the PMC as important parts of educational designs.

In the study, the CF proved to be a promising basis for a design framework. However, the findings indicate that it needs to be adapted to include external actors, and interactions with these, for seamless learning in authentic settings.

Open Access This article is distributed under the terms of the Creative Commons Attribution 4.0 International License (http://creativecommons.org/licenses/by/4.0/), which permits unrestricted use, distribution, and reproduction in any medium, provided you give appropriate credit to the original author(s) and the source, provide a link to the Creative Commons license, and indicate if changes were made.

\section{References}

Albion, P. R., Tondeur, J., Forkosh-Baruch, A., \& Peeraer, J. (2015). Teachers' professional development for ICT integration: towards a reciprocal relationship between research and practice. Education and Information Technologies, 20(4), 655-673.

Anderson, T., \& Shattuck, J. (2012). Design-based research: a decade of progress in education research? Educational Researcher, 41, 16-25.

Barab, S. A. (2004). Using design to advance learning theory, or using learning theory to advance design. Educational Technology, 3, 16-20.

Biggs, J., \& Tang, C. (2011). Teaching for Quality Learning at University. Buckingham: Open University Press. 
Bransford, J. D., Brown, A. L., \& Cocking, R. R. (Eds.) (2000). How people learn: brain, mind, experience, and school. Washington, DC: National Academy Press.

Collins, A., \& Kapur, M. (2014). Cognitive Apprenticeship. In R. K. Sawyer (Ed.), Cambridge handbook of the learning sciences, revised version (pp. 479-500). Cambridge: Cambridge University Press.

Conole, G. (2014). The 7Cs of learning design: a new approach to rethinking design practice. In S. Bayne, C. Jones, M. Laat, T. Ryberg, \& C. Sinclair (Eds.), Proceedings of the 9th International Conference on Networked Learning 2014 (pp. 502-509). Networked Learning Conference: Lancaster University.

Dewey, J. (1938). Experience and education. New York: Collier Books.

Dillenbourg, P. (1999). Introduction: what do you mean by "collaborative learning"? In P. Dillenbourg (Ed.), Collaborative learning: cognitive and computational approaches (pp. 1-19). Oxford: Elsevier Science.

Elo, S., \& Kyngäs, H. (2008). The qualitative content analysis process. Journal of Advanced Nursing, 62, 107-115.

Flick, U. (2014). The SAGE handbook of qualitative data analysis. London: Sage.

Garrison, D. R., \& Anderson, T. (2003). E-learning in the twenty-first century: a framework for research and practice. London: RoutledgeFalmer.

Gravemeijer, K. P. E., \& Cobb, P. (2006). Design research from a learning design perspective. In J. Van den Akker, K. P. E. Gravemeijer, S. McKenney, \& N. Nieveen (Eds.), Educational design research (pp. 1751). London: Routledge.

Gunn, C., \& Steel, C. (2012). Linking theory to practice in learning technology research. Research in Learning Technology, 20, 1-14.

Hattie, J. A. C., \& Yates, G. (2014). Visible Learning and the Science of how we Learn. London: Routledge.

Herrington, J., \& Oliver, R. (2000). An instructional design framework for authentic learning environments. Educational Technology Research and Development, 48(3), 23-48.

Herrington, J., Revves, T. C., \& Oliver, R. (2014). Authentic learning environments. In J. M. Spector, M. D. Merrill, J. Elen, \& M. J. Bishop (Eds.), Handbook of research on educational communications and technology (4th ed., pp. 401-412). New York: Springer.

Holmberg, J. (2014). Studying the process of educational design-revisiting Schön and making a case for reflective design-based research on teachers' 'conversations with situations. Technology, Pedagogy and Education, 23(3), 293-310.

Hsieh, H.-F., \& Shannon, S. E. (2005). Three approaches to qualitative content analysis. Qualitative Health Research, 15(9), 1277-1288.

Johnson, C. M. (2016). Rethinking online discourse: improving learning through discussions in the online classroom. Education and Information Technologies, 21(6), 1483-1507.

Jonassen, D. H. (1999). Designing constructivist learning environments. In C. M. Reigeluth (Ed.), Instructional-design theories and models (Vol. 2). Mahwah: Lawrence Erlbaum.

Kirkwood, A., \& Price, L. (2014). Technology-enhanced learning and teaching in higher education: what is 'enhanced' and how do we know? A critical literature review. Learning. Media and Technology, $39(1), 6-36$.

Koehler, M. J., \& Mishra, P. (2009). What is technological pedagogical content knowledge? Contemporary Issues in Technology and Teacher Education, 9(1), 60-70.

Kozulin, A. (2003). Psychological tools and mediated learning. In I. A. Konzulin, B. Gindis, V. Ageyev, \& S. Miller (Eds.), Vygotsky's educational theory in cultural context. Cambridge: Cambridge University Press.

Laurillard, D. (2002). Rethinking University teaching: A conversational framework for the effective use of learning technologies (2nd ed.). London: RoutledgeFalmer.

Laurillard, D. (2012). Teaching as a design science: building pedagogical patterns for learning and technology. London: RoutledgeFalmer.

Looi, C.-K., Seow, P., Zhang, B., So, H.-J., Chen, W., \& Wong, L.-H. (2010). Leveraging mobile technology for sustainable seamless learning: a research agenda. British Journal of Educational Technology, 41(2), 154-169.

Luckin, R. (2008). The learner centric ecology of resources: a framework for using technology to scaffold learning. Computers \& Education, 50, 449-462.

Marton, F., \& Pang, M. F. (2006). On some necessary conditions of learning. Journal of the Learning Sciences, 15(2), 193-220.

McKenney, S., \& Reeves, T. C. (2012). Conducting educational design research. London: Routledge.

Miles, M. B., \& Huberman, A. M. (1994). Qualitative data analysis: An expanded sourcebook (2nd ed.). Thousand Oaks, CA: Sage Publications.

Papert, S. (1980). Mindstorms. children, computers and powerful ideas. New York: Basic books.

Plomp, T., \& Nieveen, N. (Eds.) (2013). Educational design research: introduction and illustrative cases. Enschede: SLO Netherlands Institute for Curriculum Development. 
Reeves, T. C., McKenney, S., \& Herrington, J. (2011). Publishing and perishing: The critical importance of educational design research. Australian Journal of Educational Technology, 27, 55-65.

Rogoff, B. (1995). Observing sociocultural activity on three planes: participatory appropriation, guided participation, and apprenticeship. In J. V. Wertsch, P. del Rio, \& A. Alvarez (Eds.), Sociocultural studies of mind (pp. 139-164). Cambridge: Cambridge University Press.

Sandoval, W. A. (2004). Developing learning theory by refining conjectures embodied in educational designs. Educational Psychologist, 39(4), 213-223.

Sawyer, R., K. (Ed.) (2014). The cambridge handbook of the learning sciences (Second Edition). Cambridge University Press: Cambridge.

Selwyn, N. (2012). Ten suggestions for improving academic research in education and technology. Learning, Media and Technology, 37, 213-219.

Sharples, M., Taylor, J., \& Vavoula, G. (2007). A theory of learning for the mobile age. In R. Andrews \& C. Haythornthwaite (Eds.), The sage handbook of elearning research (pp. 221-247). London: Sage.

Siemens, G. (2005). Connectivism: a learning theory for the digital age. International Journal of Instructional Technology and Distance Learning, 2(1), 3-10.

Skolverket [Swedish National Agency for Education] (2011). Läroplan, examensmål och gymnasiegemensamma ämnen för gymnasieskola 2011. [Curriculum, examination goals and shared subjects for upper secondary schools 2011] Stockholm: Skolverket

Spector, J. M., Merrill, M. D., Elen, J., \& Bishop, M. J. (Eds.) (2014). Handbook of research on educational communications and technology (4th ed.). New York: Springer.

Stahl, G., Koschmann, T., \& Suthers, D. (2014). Computer-supported collaborative learning: an historical perspective. In R. K. Sawyer (Ed.), Cambridge handbook of the learning sciences, revised version (pp. 479-500). Cambridge: Cambridge University Press.

Tallvid, M. (2016). Understanding teachers' reluctance to the pedagogical use of ICT in the 1:1 classroom. Education and Information Technologies, 21(3), 503-519.

Tambouris, E., Zotou, M., \& Tarabanis, K. (2014). Towards designing cognitively-enriched project-oriented courses within a blended problem-based learning context. Education and Information Technologies, $19(1), 61-86$.

Vrasidas, C. (2015). The rhetoric of reform and teachers' use of ICT. British Journal of Educational Technology, 46(2), 370-380.

Vygotsky, L. S. (1986). Thought and language. Cambridge: MIT Press.

Wang, L. (2016). Employing Wikibook project in a linguistics course to promote peer teaching and learning. Education and Information Technologies, 21(2), 453-470.

Wastiau, P., Blamire, R., Kearney, C., Quittre, V., Van de Gaer, E., \& Monseur, C. (2013). The use of ICT in education: A survey of schools in Europe. European Journal of Education, 48(1), 11-27.

Weick, K. E. (1995). Sensemaking in organizations. Thousand Oaks: Sage Publications.

Wenger, E. (1998). Communities of practice: learning, meaning and identity. New York: Cambridge University Press.

Wertsch, J. V. (1991). Voices of the mind: a sociocultural approach to mediated action. Cambridge: Harvard University Press.

Wong, L. H., Milrad, M., \& Specht, M. (2015). Seamless learning in the age of mobile connectivity. Singapore: Springer.

Yun Dai, D. (Ed.) (2012). Design research on learning and thinking in educational settings. Enhancing intellectual growth and functioning. New York: Routledge.

Zheng, B., Niiya, M., \& Warschauer, M. (2015). Wikis and collaborative learning in higher education. Technology, Pedagogy and Education, 24(3), 357-374.

Zittoun, T., \& Brinkmann, S. (2012). Learning as meaning making. In N. M. Seel (Ed.), Encyclopaedia of the sciences of learning. (pp. 1809-1811). US: Springer. 